\title{
Clinical Follow-Up Nursing Quality in Child Health
}

\author{
Fábia Barbosa de Andrade1, Tainara Lôrena dos Santos Ferreira1, \\ Tiago José Barbosa de Andrade2 , Jéssica Isabelle dos Santos Dutra1, \\ Dídia de Oliveira Pereira1, Brenda Kalyny Silva1, Íngrid Katianne Marques Araújo ${ }^{1}$ \\ ${ }^{1}$ Faculty of Health Sciences of Trairi (FACISA), Federal University of Rio Grande do Norte (UFRN), \\ Santa Cruz, Brazil \\ ${ }^{2}$ University Center of João Pessoa (UNIPÊ), João Pessoa, Brazil \\ Email: fabiabarbosabr@yahoo.com.br, tainara lorena@hotmail.com, tiagobarbosajp@yahoo.com.br, \\ jessicabellejp@hotmail.com, didia oliveira@hotmail.com, breeendiinha@hotmail.com, \\ ingridkati@hotmail.com
}

Received 1 September 2015; accepted 27 September 2015; published 30 September 2015

Copyright (C) 2015 by authors and Scientific Research Publishing Inc.

This work is licensed under the Creative Commons Attribution International License (CC BY). http://creativecommons.org/licenses/by/4.0/

(c) (7) Open Access

\begin{abstract}
Objective: The present work aims to evaluate the impact of the activities of nursing consultations on health conditions of children served in Clínica de Enfermagem Salvando Vidas com Educação. Methods: This is an exploratory, descriptive study with a quantitative approach, realized from January through December 2012, at the Clínica de Enfermagem (Nursing Clinic), in the Santa Cruz County, Rio Grande do Norte's countryside, Brazil. Results: The obtained results showed a significant correlation between the type of pathology and final treatment proven by the value of $p=$ 0.000; as for assessed $60 \%$, more than half were discharged; the most prevalent diseases were the association between cutaneous and gastric with $11 \%$ who were discharged and, lastly, the association between gastric and respiratory with $7 \%$ discharged. Conclusion: Thus, the activities developed by the project are not restricted to the examination during the nursing consultation, since educational activities are planned from the data obtained in those consultations.
\end{abstract}

\section{Keywords}

Child, Nursing, School, Care

\section{Introduction}

The health care for children is a priority on the health agenda in all States of Brazil, because it provides for the

How to cite this paper: de Andrade, F.B., dos Santos Ferreira, T.L., de Andrade, T.J.B., dos Santos Dutra, J.I., de Oliveira Pereira, D., Silva, B.K. and Araújo, Í.K.M. (2015) Clinical Follow-Up Nursing Quality in Child Health. Health, 7, 1235-1242. 
implementation of a set of actions of disease prevention and health promotion to reduce the rates of illness and mortality.

Childcare is complex and requires several elements in the care action. To this end, the Programa de Atenção Integral à Saúde da Criança (PAISC) (Integral Attention to the Health of the Child Program) has proposed the assistance organization and involves a whole network of services, in order to obtain epidemiological impact on possible harms on child health. From this perspective, it is necessary that professionals, staff, institution and health units should be prepared as a whole to work with multidisciplinary attention, using an integrated way to do and think and watching that is not the work of an isolated professional [1].

The health care of children in Brazil has been developed under the public assistance through the work of the multidisciplinary team involving professionals as a doctor, dentist, nurse, psychologist, among others. This initiative of the understanding is that health is integral, universal and equitable versa as the Brazilian constitution, i.e. a health care quality should receive a qualified professional attention from all segments of this team.

In 2004, the Ministry of health published the Agenda de Compromissos para a Saúde Integral da Criança e Redução da Mortalidade Infantil (Commitment to the Integral Health of Child and Infant Mortality Reduction Agenda). Among many attributes, it's highlighted: the appropriate reception to children seeking the service, with simple or complex problems, so that makes it a qualified efficaciousness; identifies in the child signs of risk and prioritizes care, sending to a specialist when necessary; maintains childcare, home visits and returns; searches for children that do not return to the service; accompanies children forwarded to secondary attention and promotes educational groups monthly, open to the community for the mothers or guardians, so that an integral attention to the child and its family is possible [2].

In the performance of the child health program, there are several queries. Among them, Nursing shows the quality of nursing care to children from birth to two years to complete. In this sense, the Universidade Federal do Rio Grande do Norte has the extension project Salvando Vidas com Educação. It works since 2011 and has the nursing care for children and adolescents as its main focus, aiming at the promotion and prevention of diseases. This project aims at clinical follow-up and also the continuity of assistance at Clínica de Enfermagem Salvando Vidas com Educação, keeping this way an interrelation with the other health services in the County.

That way, there needs to be persistency of the integral monitoring and assistance to children in all instances of health services, so that the resolution of the harms to health is guaranteed.

In Brazil, socioeconomic inequalities, evidenced in the Northeast, are associated with the role played by the infectious diseases, particularly acute diarrhea and acute respiratory infection (ARI), which are still presented as a cause of death in children, even after significant changes that are happening in the epidemiological profile of morbidity and mortality in children under-five [3].

With that, the integrality is the principle of health policy that points to the understanding that the factors that interfere in child health are vast and include several other sectors besides health. Therefore, this attribute consists in providing by the health team, a set of services that meet the most common needs of the population to be served in the unit as the proper recognition of the problems associated with the diseases outbreak and accountability for other points of attention to health results in the offer of preventive and curative services, as well as the guarantee of various types of services [1] [4].

Attention to the child's health must be presented in any opportunity that presents itself, whether in the health unit, at home or in public spaces, such as daycare centers, preschools and schools. And, consequently, a multidisciplinary and comprehensive care that is able to understand all their needs and rights as individuals is given to the child as it is essential to promote access to attention at all levels: from health to more complex level of assistance, the locus of health care to other sectors that have closer link with health, such as housing conditions, treated water, education, among others [2].

The child care in the primary care network has as its central focus the monitoring of child growth and development, encourage breastfeeding, nutrition guidelines for each stage of development, immunization, accident prevention and care prevalent disease of childhood, which are fundamental in the practices and health conditions [5].

An important assistance to the child is the puericulture, which presents itself as a fundamental object for the integral care during growth and child development, and focuses on prevention, health promotion and protection, in order for the child to reach its adulthood without complications from childhood. Given the above, when a nursing query in child welfare is performed it has as its objective an integral service to the child, so that the assistance is not focused only on diseases, but on the whole child, since by means of the query you can monitor, 
evaluate, and intervene in case of health/disease [6].

It is of great importance that the professionals responsible for carrying out puericulture consultations are not only be restricted the disease itself, but that they realize procedures aimed at the prevention and promotion of health of these children. That is, one should not look at these children only by injury that affects them, but rather fully, so that the assistance offered is the most appropriated possible.

Child welfare nursing consultations also must address environmental factors, considering that the questions about the child's development, style and living conditions, psychological problems and family environment are a part of professional practice, and it is important to develop the basis for health promotion, so even the relationship with the family can be improved [6] [7].

Consider the child's attention on the network is to recognize that basic health care presents different meanings based on the value of life and human dignity. Is to understand that the care takes place in the communication, participation, and collaboration among health professionals responsible for assistance and the families of the children served [1].

On the face of it, the child has a higher vulnerability to problems related to health, when these are dependent on its life conditions. Thus, it is necessary to have knowledge of the harms that occur in childhood, its prevalence, its risk factors, methods of presentation and possible treatment options, as well as prevention and health promotion, in order that a greater control in child morbidity and mortality rates is possible.

Therefore, considering the University's commitment to the community, from the points of interest of the population of the neighborhood where the Nursing clinic is located and the fact that being the most needy and populous district and of the city, in addition to not having adequate sanitation, it is observed that there is a need to assess the impact of the nursing consultations, through a proposed intervention study consisting in care of the child together with the students and nurse teacher, on health conditions of children served at the Clínica de Enfermagem Salvando Vidas com Educação.

\section{Methodology}

This is an exploratory, descriptive study with a quantitative approach, realized from January through December 2012, at the Clínica de Enfermagem, located in Paraiso, in the Santa Cruz County, Rio Grande do Norte's countryside, Brazil. The sample was chosen not probabilistic and random way, was composed of 184 children who are registered and monitored by the nursing staff. In the community where the study was conducted sixteen thousand persons reside with socio-economic situation of poverty, deprivation and vulnerability condition. The questionnaire was developed with relevant child health issues as well as the cast of nursing interventions, which, as care was implemented in children, were registered in the hospital records of the children.

How instrumeto data collection of clinical consulting a roadmap developed by the researchers was used according to the roadmap of health care to the child. Shortly thereafter, the results were stored in a database for each child. The children were chosen, and requested the presence of the parent or guardian so that the query was performed in a private clinic setting, which involved direct assistance with medical history and physical examination.

The inclusion criterion was to be a child or adolescents and be registered in the project. Because it is a quantitative research, data were tabulated and submitted to analysis in the Statistical Package for the Social Sciences, SPSS version 22.0, version 10101141047. For analysis of the data were calculated the descriptive statistical measures as average, median and standard deviation. In bivariate analysis, Chi-square tests were performed, with significance level as a probability of less than $0.05 \%$ and $95 \%$ confidence interval.

The study followed all the recommendations contained in the resolution 466/2012 National Health Council, regarding research with human beings. The project was submitted and approved by the Ethics and Research Committee (ERC), from the Federal University of Rio Grande do Norte (UFRN) under number 348.897.

\section{Results}

The study comprised 184 (100\%) children served at the Clínica de Enfermagem Salvando Vidas com Educação, with an average age of 10 years, median of 11 years and the standard deviation of 9.12. In Brasil, as children are classified as neonatal (up to 28 days old), infants (from one to twelve months), preschool (one to six years) and children (seven to twelve years).

The following results will be revealed as the joint research of care in child health, divided as follows: more health problems found among children; therapy of disease prevention; set of guidelines on health passed on to 
children and families; returns requested for monitoring clinical outcome and, finally, the end conduit.

Was perceived significant correlation between age and type of Pathology, proven by the value of $p=0.03$, deserving prominence the following diseases: Cutis with $19.7 \%(\mathrm{n}=39)$, cutaneous and gastric with $16.7 \%(\mathrm{n}=$ 33), gastric with $13.1 \%(n=26)$, gastric and respiratory with $8.1 \%(n=16)$ and respiratory with $7.1 \%(n=14)$. A significant correlation between sex and type of Pathology Was reached, confirmed by the value of $p=0.044$. Deserving highlights the female, in which every disease was more prevalent with 52.5\% $(\mathrm{n}=104)$, and the males with $47.5 \%(n=94)$.

According to Table 1, there was significant correlation between existing diseases and therapeutics held, fact proven by the value of $p=0.00,184$ children were attended (100\%), but only 165 (89.67\%) were diagnosed with any pathology, 96 (52.17\%) were given drug therapy and the 69 (37.5\%) remaining were not treated, since they did not returned accompanied by the responsible person.

As seen in Table 2, was perceived significant correlation between the treatments held according to the pathology, which is confirmed by the value of $p=0.000$. Then, referring to the clinic attendances, $63(31.8 \%)$ received orientation and prescriptions, followed by 49 people that received guidelines (24.7\%), other 33 (16.7\%) children were driven to return and 24 (12.1\%) had orientation on oral and personal hygiene. The set of guidelines for child health are about the basic issues for child as oral hygiene and body, healthy eating practices of leisure and entertainment activities.

In Table 3, the significant correlation between the treatment and the pathology was proved the value of $p=$ 0.023 , in which 98 (81.7\%) of the assessed were affected by some pathology and of these, 59 (49.2\%) were discharged, 25 (20.8\%) were in treatment and 14 (11.7\%) were referred to the specialists. The remaining 22 (18.3\%) evaluated were not affected by pathology. Of these, 20 (16.63\%) were discharged, $1(0.83 \%)$ continued in treatment and $1(0.83 \%)$ was transferred.

Table 4 shows the significant correlation between the final treatment and the return, determined by the value of $p=0.000$, in which $55 \%$ (66) of the evaluated had return and of these, $26.7 \%$ (32) were discharged, $20.8 \%$ (25) remained in treatment and 7.5\% (9) were referred to specialists. $45 \%$ (54) of the remaining evaluated did not return and of these, 39.17\% (47) were discharged, $0.83 \%$ (1) was undergoing treatment and $5 \%$ (6) were forwarded to specialists.

As to the significant correlation between the type of pathology and final treatment, was evidenced by the value of $p=0.000$, that $60 \%$ (60) of the assessed were discharged, $26 \%$ (26) remained in treatment and 14\% (14)

Table 1. Correlation of pathologies and completion of therapy. Santa Cruz/RN, Brazil, 2013.

\begin{tabular}{ccccc}
\hline & \multicolumn{2}{c}{ Pathology } & Total \\
\hline \multirow{2}{*}{ Therapy } & Yes & $52.17 \%(\mathrm{n}=96)$ & $0.0 \%(\mathrm{n}=0)$ & $52.17 \%(\mathrm{n}=96)$ \\
& No & $37.5(\mathrm{n}=69)$ & $10.33 \%(\mathrm{n}=19)$ & $47.83 \%(\mathrm{n}=88)$ \\
\hline
\end{tabular}

Table 2. Ducts used in relation to diseases. Santa Cruz/RN, Brazil, 2013.

\begin{tabular}{ccccccc}
\hline $\begin{array}{c}\text { Guidelines and } \\
\text { medical products }\end{array}$ & $\begin{array}{c}\text { General } \\
\text { guidelines }\end{array}$ & $\begin{array}{c}\text { Return } \\
\text { guidelines }\end{array}$ & $\begin{array}{c}\text { Hygiene } \\
\text { guidelines }\end{array}$ & $\begin{array}{c}\text { Drug } \\
\text { prescription }\end{array}$ & $\begin{array}{c}\text { Medical products } \\
\text { and exam request }\end{array}$ & $p<0.05$ \\
$31.8 \%(\mathrm{n}=63)$ & $24.7 \%(\mathrm{n}=49)$ & $16.7 \%(\mathrm{n}=33)$ & $12.1 \%(\mathrm{n}=24)$ & $4.0 \%(\mathrm{n}=8)$ & $3.5 \%(\mathrm{n}=7)$ & 0.000 \\
\hline
\end{tabular}

Table 3. Correlation between behavior and pathology. Santa Cruz/RN, Brazil, 2013.

\begin{tabular}{|c|c|c|c|c|c|}
\hline \multicolumn{6}{|c|}{ Pathology } \\
\hline & & Yes & No & Total & $p<0.05$ \\
\hline \multirow{3}{*}{ Conduct Final } & High & $49.2 \%(n=59)$ & $16.63 \%(n=20)$ & $65.83 \%(n=79)$ & \\
\hline & In treatment & $20.8(n=25)$ & $0.83 \%(n=1)$ & $21.63 \%(n=26)$ & 0.023 \\
\hline & Forwarded & $11.7 \%(n=14)$ & $0.83(\mathrm{n}=1)$ & $12.53 \%(\mathrm{n}=15)$ & \\
\hline
\end{tabular}


Table 4. Correlation between the final return and treatment. Santa Cruz/RN, Brazil, 2013.

\begin{tabular}{cccccc}
\hline & \multicolumn{3}{c}{ Return } & & \\
\hline & & Yes & Total & $p<0.05$ \\
\hline \multirow{3}{*}{ Conduct final } & High & $26.7 \%(\mathrm{n}=32)$ & $39.2 \%(\mathrm{n}=47)$ & $65.8 \%(\mathrm{n}=79)$ & \\
& In treatment & $20.8(\mathrm{n}=25)$ & $0.8 \%(\mathrm{n}=1)$ & $21.7 \%(\mathrm{n}=26)$ & 0.000 \\
& Forwarded & $7.5 \%(\mathrm{n}=9)$ & $5.0(\mathrm{n}=6)$ & $12.5(\mathrm{n}=15)$ & \\
\hline
\end{tabular}

were forwarded. As regards to the most prevalent pathologies, associations were perceived between gastric and cutaneous, followed by respiratory and gastric.

\section{Discussions}

The results were positive in the quality of child health. In the study in question, it was observed that in the children's age range, of 10 years, the most prevalent illnesses are disorders in the skin followed by gastric and respiratory diseases, due to the fact they have intense contact with several children and do not present an effective self-care. Another relevant point to the high prevalence of these diseases is the lack of knowledge on the part of the responsible/family and children about the causes, treatment and prevention of such diseases.

Therefore, it is up to the nursing clinic to perform educational activities so children can be multipliers of information and thus minimize the high rates of these diseases. In addition to the consultations in their integral form, the patients are observed throughout their socioeconomic context, so that the therapy is as correct as possible. The nursing staff always involves the family as co-responsible for the continued care and disease prevention for children. It is worth remembering that in Brazil, since 1994, the Programa Saúde na Família (PSF) (Health in the family Program) was implemented, whose proposal is to have the family as an integral and supportive care focus. This shows the importance of continued intervention of professional nurses in primary health care and quality education that should be provided by public universities closer to the reality of the community and the needs of the population healthcare professional.

Nursing offers health assistance not only with the care itself, but also by means of educational activities developed primarily in the places where a greater number of children and adolescents can be found, with the intention that they can be multipliers of information and these, in turn, can guide the nurses about the more apparent harms to health in each community and to continue the assistance of individuals [8].

In this study, it was noted that the vast majority of most prevalent diseases involved females. In this way, the project Salvando Vidas com Educação must maintain effective communication with the community where it is inserted, in order to know the population's socio-demographic profile, as well as the range of the population's main health needs, in addition to ensuring through its educational activities and consultations, the continuity of assistance the person assisted.

Significant differences in the distribution by sex, with higher prevalence in girls than in boys were also found. This is because the girls have higher interpersonal contact, for longer and more intimate than the boys [9].

Another point to be discussed is the issue of commitment and concern of parents with their children's health, because there is no way to health professionals and, in this context, nursing, to perform a quality assistance for children if the mother/father/guardian do not attend to consultations/returns with them, to receive treatment guideline once the minor cannot be solely responsible for its health. For that reason so many are without the necessary therapy to combat existing pathologies, and end up in grave situations, that can bring greater health system expenditures. As shown in Table 1 and Table 2, it can be to see the need for attention to the most common diseases, according to the profile of the epidemiology of each region, as well as revealing the degree of impairment of children's health and what orientations and behaviors necessary for a preventive efficacy outcome with and without mortality risks.

To this end, it is necessary to create links with the families, provide dialogues on issues of their interest and desires experienced at home, in order to stimulate them to recognize the importance they have in maintaining the health of the whole family, with the aim of contributing to the increase in care and apprehend it in an integrative perspective, contingent, longitudinal and sufficiently good and effective [5].

However, there's still the factor of efficaciousness in consultations according to the case presented, what makes necessary to have an effective assistance, with oral and body hygiene orientation, of how to follow the 
treatments correctly or ways to have a healthy lifestyle, so that, in addition to treat this disease, prevent the emergence of possible ones in the future.

Thus, it is normally realized that health actions must be objectified in the logic of the care, with activities focused on solving the problems, the needs and the quality of life of users, acting in hegemonic assistance model that influences the performance of professionals and managers, and mobilizes the population in search of autonomy and participation of its health-related interests [10].

With regard to the correlation between the treatment and the pathology, most patients were discharged, since received the right treatment and recovered their health; others were undergoing treatment and some required specialized attention.

In Brazil, the Conselho Federal de Enfermagem (COFEN) (Federal Council of Nursing Care), through resolution No. 317/2007 which revoked resolution No. 271/2002, points out that it is the nurse's competence the completion of the nursing consultation, prescription medicines and examination request in the institutions that have approved protocols [11]. In this sense, all services of primary base in Brazil, such as the Atenção Primária à Saúde (APS) (Primary Health Care), which operates the childwelfare, possess the professional nurse responsible for the health care of the child.

One of the activities of the nurse in the APS is to perform the nursing consultation. It is through the consultation that the needs can be identified and thus establish effective treatments to behold such findings as proposed by the Ministry of Health to retrieve the state of health of the child and the family, this can be seen in Table 2, which is the set of directions needed.

On the correlation between the final consultation and the return, seen in Table 3 and Table 4, the majority of patients were scheduled to come back, however the discharges were higher for those who do not require return, because for those who were scheduled to return, some were still undergoing treatment. Others were discharged, and a minority has been forwarded to specialists. Meaning, therefore, that the majority of patients have received the appropriate treatment, recovered his health and were discharged and others were still in the process of recovery.

The results show the importance of continued intervention of health care to the child, as the search for returns reveal the need for monitoring the most vulnerable situations which lead to bring this child quickly to end the pathological situation in which she finds herself. It is worth remembering that the disease is not cured of situations can lead to a social and community aggravation of diseases, which makes it harder to control endemic and the reach of a concept of integral health and quality in Brazil.

With regard to the correlation between final treatment and type of pathology, the ones that affected most the assessed were the gastric and cutaneous, both in their isolated form as associates. The discharge percentage of children who were still in treatment was also greater for these pathologies, which reflects the great prevalence of the same. The study that evaluated the causes of hospitalizations of children considered sensitive to primary attention identified that the respiratory, gastrointestinal disorders and skin, such as pneumonias, gastroenteritis and fungal infections are most prevalent in children [12].

This fact demonstrates the fragility of the primary care services and makes one think about the importance of early identification and treatment of these disorders. Soon, the results show both the effectiveness in evaluations as in established consultations, in acting under the children's vulnerabilities.

Other pathologies prevalent among the assessed were respiratory diseases, but all patients were discharged. If at the first symptoms is not given the importance, the child does not receive proper care, which can make the problem even more severe or persistent [13]. The study shows pertinent data to effective and resolutive performance to the children with respiratory diseases, considering that all were treated and recovered their health. These data corroborate the epidemiological studies of the Health Ministry, when punctuate respiratory diseases and parasitic diseases as more prevalent in child health.

This further contributes to the quality of teaching health nursing in Brazil, because it is a growing country and expansion of new universities and courses that require a satisfactory quality of education process in health. Accordingly, the supervisory bodies should monitor the progress and improvement needs of nursing student who needs to be close to reality to become a professional future with better profile assistance and protagonist of quality care within the framework of child health.

\section{Conclusions}

The data of children served in Nursing Practice Salvando Vidas com Educação have shown a distinctive and 
positive clinical follow-up, provided by nursing staff and characterized by the attributes of responsibility, efficaciousness and commitment with the user of the Sistema Único de Saúde (SUS). The results showed that at any time the kids were without continued assistance, because the assistance reference levels were respected so the proper treatment could be performed. And yet, when the treatment didn't use any drugs, the members of the project provided specific and general guidance to caregivers and the children attended.

Therefore, the data revealed the commitment to child health and their families by acknowledging the zeal and dignity in a quality assistance, because it sought to act from the understanding of collaboration in health of the University with the needy community, which required a dignified care.

Also, the activities developed in the clinic are not restricted to the examination during the nursing consultation, since the data obtained during the consultations help educational activities that may be oral, personal hytransmission and treatment of these diseases, because that is the best way to try to lessen the prevalence of diseases if considered that the target audience of the actions are children likely to disseminate the knowledge transmitted, that is, multipliers of knowledge. This study has limitations of understanding the amount of accompanied children and the low participation of parents or guardians.

It should be emphasized that this study is being developed software that will be deployed in the Clinical School of Nursing to work in the form of electronic records and is integrated with other health services in the city of Santa Cruz. This makes the information valuable health and well stored with more applicability in the clinical follow-up of treated patients.

All actions carried out by the clinic meet what is proposed by the Ministry of health, when the measures of health promotion and disease prevention in child welfare in primary health network are elaborated, as well as when the family is chosen as continued care core, with a view to achieving effective clinical follow-up, able to identify diseases in a timely manner and the resolution of health needs and, with this avoid the opportunities of hospitalization and expenses and burden caused to the Brazilian health care system.

\section{References}

[1] Sousa, F.G.M. and Erdmann, A.L. (2012) Qualifying child care in Primary Health Care. Revista Brasileira de Enfermagem, 65, 795-802. http://www.scielo.br/pdf/reben/v65n5/12.pdf

[2] Brasil. Ministério da Saúde. Secretariat of Health Care. Department of Strategic Programmatic Actions (2004) Datebook for Comprehensive Child Health and Reducing Child Mortality. Ministério da Saúde, Brasília. http://bvsms.saude.gov.br/bvs/publicacoes/agenda_compro_crianca.pdf

[3] Vazquez, M.L., Mosquera, M., Cuevas, L.E., González, E.S., Veras, I.C.L., Luz, E.O., et al. (1999) Incidence and Risks Factors for Diarrhoea and Acute Respiratory Infections in Urban Communities of Pernambuco, Brazil. Cadernos de Saúde Pública [Online], 15, 163-172. http://dx.doi.org/10.1590/S0102-311X1999000100016

[4] Leão, C.D.A., Caldeira, A.P. and Oliveira, M.M.C. (2011) Aspects of Primary Care For Children: An Evaluation of CareGivers. Revista Brasileira de Saúde Materno Infantil [Online], 11, 323-334. http://dx.doi.org/10.1590/S1519-38292011000300013

[5] Mello, D.F., Furtado, M.C.C., Fonseca, L.M.M. and Pina, J.C. (2012) Child Health Follow-Up and the Longitudinality of Caring. Revista Brasileira de Enfermagem [Online], 65. http://www.scielo.br/pdf/reben/v65n4/a18v65n4.pdf

[6] Gauterio, D.P., Irala, D.A. and Cezar-Vaz, M.R. (2012) Childcare in Nursing: Profile and Main Problems Found in Children Less than One Year. Revista Brasileira de Enfermagem [Online], 65, 508-513. http://www.scielo.br/pdf/reben/v65n3/v65n3a17.pdf

[7] Ciftci, I.H., Karaca, S., Dogru, O., Cetinkaya, Z. and Kulac, M. (2006) Pediculosis and Scabies Infestation among Preschool Nursery Children. Korean Journal of Parasitology, 44, 95-98. http://www.ncbi.nlm.nih.gov/pmc/articles/PMC2532640

[8] lori Pbert, et al. (2013) A School Nurse-Delivered Intervention for Overweight and Obese Adolescents. Journal of School Health, 83, 182-193. http://onlinelibrary.wiley.com/doi/10.1111/josh.2013.83.issue-3/issuetoc

[9] Ríos, S.M., Fernández, J.A., Rivas, F., Sáenz, M.L. and Moncada, L.I. (2008) Prevalencia y factores asociados a la pediculosis en niños de un jardín infantil de Bogotá. Biomédica, 28, 245-251. http://dx.doi.org/10.7705/biomedica.v28i2.95

[10] Costa, G.D., Cotta, R.M.M., Reis, J.R., Ferreira, M.L.S.M., Reis, R.S. and Franceschini, S.C.C. (2011) Evaluating Child Healthcare in the Context of Family Healthcare in the City of Teixeiras, Minas Gerais (MG, Brazil). Ciência \& Saúde Coletiva [Online], 16, 3229-3240. http://www.scielosp.org/pdf/csc/v16n7/22.pdf.

[11] (2002) Conselho Federal da Enfermagem-COFEN. Portal COFEN. 
http://novo.portalcofen.gov.br/resoluo-cofen-3172007_4351.html

[12] Caldeira, A.P., Fernandes, V.B.L., Fonseca, W.P. and Faria, A.A. (2011) Admissions to Pediatric Hospital for Conditions Amenable to Primary Care in Montes Claros, Minas Gerais, Brazil. Revista Brasileira de Saúde Materno Infantil [Online], 11, 61-71. http://www.scielo.br/pdf/rbsmi/v11n1/a07v11n1.pdf

[13] Sousa, C.A., César, C.L.G., Barros, M.B.A., Carandina, L., Goldbaum, M. and Pereira, J.C.R. (2012) Respiratory Diseases and Associated Factors: Population-Based Study in São Paulo, 2008-2009. Revista de Saúde Pública [Online], 46, 16-25. http://www.scielo.br/scielo.php?pid=S0034-89102012000100003\&script=sci_abstract\&tlng=pt 